\title{
Lipase catalysed Michael addition of secondary amines to acrylonitrile
}

\author{
Oliver Torre, Ignacio Alfonso and Vicente Gotor* \\ Departamento de Química Orgánica e Inorgánica, Universidad de Oviedo, C/Julián Clavería, 8, E-33071 \\ Oviedo, Spain. E-mail: vgs@sauron.quimica.uniovi.es; Fax: +34 985103448; Tel: +34 985103448
}

Received (in Cambridge, UK) 13th February 2004, Accepted 11th June 2004

First published as an Advance Article on the web 28th June 2004

A new enzymatic process is described. Different preparations of lipase B from Candida antarctica are able to catalyse Michaeltype addition of secondary amines to acrylonitrile. This new reaction widens the applicability of these biocatalysts in organic synthesis.

The use of enzymes for organic synthesis has become an interesting area for organic and bioorganic chemists. Since many enzymes have demonstrated their activity with nonnatural substrates in organic media, they have become widely used to carry out synthetic transformations. 1 Among all of them, hydrolases and especially lipases are the most used enzymes due to their high stability and activity with a broad spectrum of substrates. Besides, many of them are commercially available; they work under mild reaction conditions and without cofactor.

During our work devoted to exploring new synthetic applications of biocatalysts, we have found that some hydrolases are able to catalyse different reactions from the natural process that they usually promote. For instance, some lipases are able to catalyse aminolysis and ammonolysis reactions. ${ }^{2}$ In a recent paper, an engineered mutant of CAL B was developed to catalyse carboncarbon bond forming reactions. ${ }^{3}$ The mutants Ser105Ala and Ser105Gly, which lack the nucleophilic serine residue in the catalytic triad, showed a clear aldolase activity. Surprisingly, the wild type enzyme is also able to promote that reaction, although to a lower extent. With the help of theoretical calculations, the authors propose a mechanism in which the oxyanion hole of the active site stabilizes the negative charge of the transition states and the HisAsp pair serves as a proton shuttle. Considering that mechanism, we envisioned that this enzyme could also catalyse Michael addition. In a preliminary paper, a report regarding this possibility was published, but in that case a covalent acyl-enzyme intermediate can be formed. ${ }^{4}$ Here we report the unprecedented lipase-catalysed Michael addition of a secondary amine to acrylonitrile. In our case, although a covalent acyl-enzyme intermediate is prevented, the catalytic effect of the lipase is clearly demonstrated.

The reaction of acrylonitrile with different secondary amines in the presence of lipase B from Candida antarctica led to the corresponding Michael adduct faster than in the absence of the biocatalyst. We have followed the formation of the products by GC in order to quantify their concentration and compare reaction rates. $\uparrow$ Results of initial rates with different amines and biocatalysts are summarised in Table 1 . In all cases CAL B is able to catalyse the reaction, up to 100-fold faster than the process in absence of biocatalyst. Among two different CAL B preparations, Chirazyme L-2 is more efficient than Novozyme 435 for the process. The initial rate is practically proportional to the enzyme amount (entries 3 and 4), suggesting the catalytic effect of the enzyme. The reaction

$\mathrm{R}_{1}$<smiles>[R]N[NH+]=CCNCC#N</smiles>

$\mathrm{R} 1, \mathrm{R} 2$

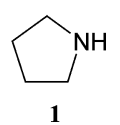<smiles>C1CCNCC1</smiles><smiles>CCNCC</smiles>

Scheme 1 also takes place with cyclic and non-cyclic amines and the reaction rates depend on the amine structure. In this preliminary communication, specific data for pyrrolidine $\mathbf{1}$, piperidine $\mathbf{2}$ and diethyl amine $\mathbf{3}$ are reported although other amines also react in very similar reaction conditions. The reactivity order goes from cyclic to non-cyclic amines $(\mathbf{1}>\mathbf{2}>\mathbf{3})$, in good agreement with their nucleophilicity.

Taking into account these results, we performed some experiments focused on demonstrating the specific catalytic effect of the enzyme. When the enzyme (Novozyme 435) is pre-treated with urea at $100{ }^{\circ} \mathrm{C}$ in order to completely denaturalise the protein, the rate is practically equal to the background reaction (entry 6),

Table 1 Initial rates $\left(V_{\mathrm{o}}\right)$ of Michael addition between secondary amines $(0.05 \mathrm{M})$ and acrylonitrile $(0.1 \mathrm{M})$

\begin{tabular}{|c|c|c|c|c|c|}
\hline Entry & Amine & Catalyst & $\begin{array}{l}\text { Amount } \\
(\mathrm{mg})\end{array}$ & $\begin{array}{l}V_{\mathrm{o}} \\
\left(\mu \mathrm{M} \cdot \min ^{-1}\right)\end{array}$ & Vrel $^{a}$ \\
\hline 1 & 1 & - & - & 23 & 1 \\
\hline 2 & 1 & Novozyme 435 & 100 & 300 & 13.3 \\
\hline 3 & 1 & Chirazyme L-2 & 50 & 267 & 11.9 \\
\hline 4 & 1 & Chirazyme L-2 & 100 & 467 & 20.7 \\
\hline 5 & 1 & lyophilised CALB & 50 & 200 & 8.9 \\
\hline 6 & 1 & denatured $^{b}$ & 100 & 40 & 1.8 \\
\hline 7 & 1 & B.S.A. & 50 & 20 & 1 \\
\hline 8 & 2 & - & - & 8 & 1 \\
\hline 9 & 2 & Novozyme 435 & 100 & 100 & 12.5 \\
\hline 10 & 2 & Chirazyme L-2 & 100 & 300 & 37.5 \\
\hline 11 & $\mathbf{3}^{c}$ & - & - & 3 & 1 \\
\hline 12 & $3^{c}$ & Novozyme 435 & 100 & 100 & 33.3 \\
\hline 13 & $\mathbf{3}^{c}$ & Chirazyme L-2 & 100 & 300 & 100 \\
\hline
\end{tabular}

${ }^{a}$ Initial rates relative to the reaction in the absence of catalyst. ${ }^{b}$ Pre-treated with urea at $100{ }^{\circ} \mathrm{C}$ for several hours. ${ }^{c}$ These reactions were run at $0.3 \mathrm{M}$ in both amine and nitrile.

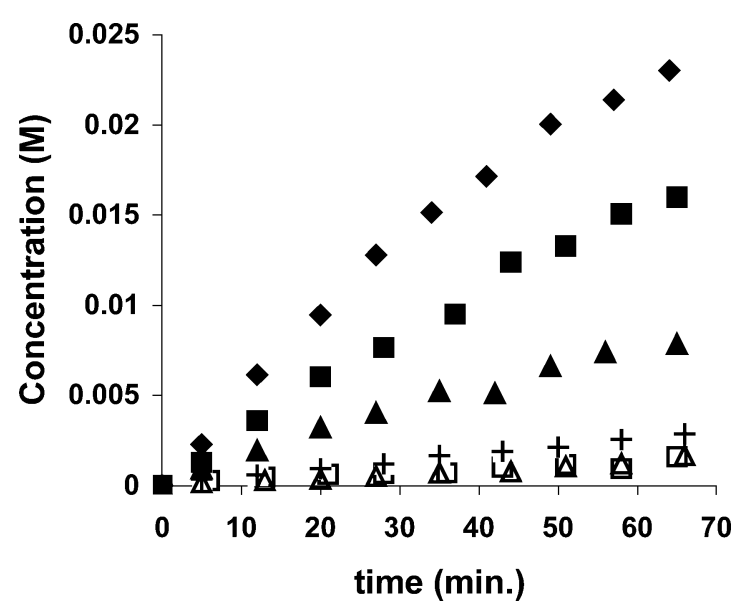

Fig. 1 Plot of the concentration of Michael adduct product of pyrrolidine $(0.05 \mathrm{M})$ and acrylonitrile $(0.1 \mathrm{M})$ versus time in the presence of: (a) no catalyst (open squares); (b) $100 \mathrm{mg}$ of CAL B Novozyme 435 (filled squares); (c) $100 \mathrm{mg}$ of CAL B Chirazyme L2 (filled diamonds); (d) $50 \mathrm{mg}$ of lyophilised CAL B (filled triangles); (e) $100 \mathrm{mg}$ of denatured CAL B Novozyme 435 (crosses); (f) $50 \mathrm{mg}$ of bovine serum albumin (open triangles). 


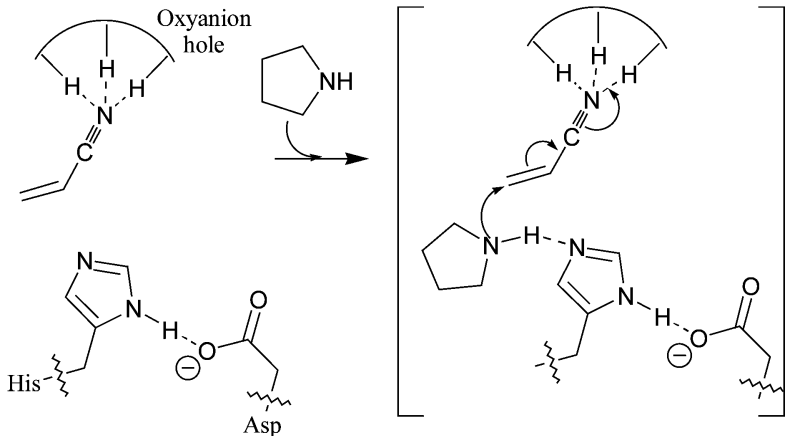<smiles>C=CNCC(C)(C)CC1CCN(CCC#N)C1</smiles>

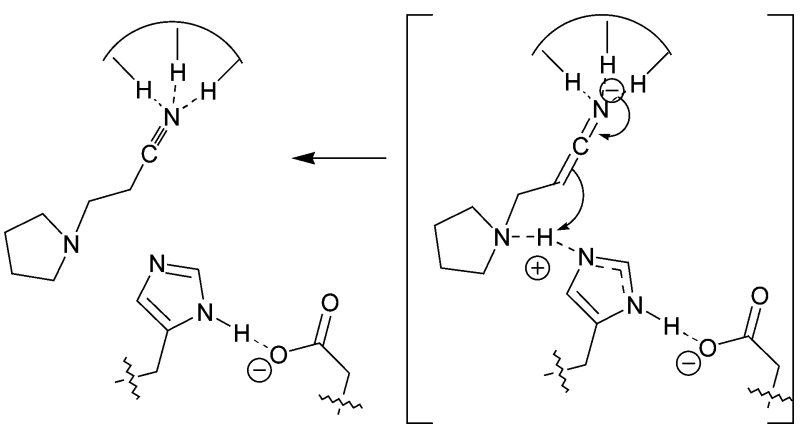

Scheme 2 Proposed mechanism of lipase catalysed Michael addition.

suggesting that the tertiary structure of the biocatalyst is necessary to promote the process. Moreover, this experiment suggests that the polymeric support has little effect on the catalysis. This has been further demonstrated by performing the reaction with lyophilised CAL B, which is also able to catalyse the Michael addition (entry 5). Although the process is less efficient, the enzyme itself can increase 9-fold the initial reaction rate. Another concern would be if the catalysis takes place in a specific way or maybe some amino acids on the enzyme surface can promote the process. Related to that, we confirmed that bovine serum albumin (B.S.A.) is unable to catalyse the same reaction (entry 7 in table 1, Fig. 1). Considering that this protein has similar amino acid distribution on its surface, this result suggests the reaction must take place in a specific fashion on the catalytic site.

We also observed that, at long reaction times, some side products coming from the acrylonitrile were formed. This presumably polymerisation process can be avoided by adding an inhibitor such us dihyroquinone to the reaction mixture. Both, reaction rate and final conversion can be improved this way.

With all these results in hand, we propose a tentative mechanism for this new process (Scheme 2). Very common catalysts for Michael reaction usually are Lewis acids ${ }^{5}$ (similar to the oxyanion hole) or an acid-base group for proton transference from the entering Michael donor nucleophile to the $\mathrm{C}-\alpha$ position of the Michael acceptor. ${ }^{6}$ In the catalytic site of a serine hydrolase both moieties are present very close in the space. The proposed mechanism would start with the accommodation of the Michael acceptor (acrylonitrile) in the active site. Interaction of the nitrile with the oxyanion hole would increase its electrophilic ability. Then, conjugated addition of the nucleophile would lead to a zwiterionic intermediate, which can be stabilised by both the oxyanion hole and the His-Asp pair. This His-Asp pair, as proposed in similar catalytic cycles, ${ }^{7}$ catalyses proton transference from the incoming nucleophile to the $\alpha$-carbon. Finally, a new Michael acceptor would shift the final product, leading to a new catalytic cycle.

In conclusion, here we report an unprecedented lipase catalysed Michael addition reaction. Initial rates with different preparations of the biocatalyst and different secondary amines are measured. The catalytic effect of the enzyme is demonstrated by the combination of different experiments. The importance of this new amino-lyase activity ranges from the fundamental study of enzymatic function to the potential synthetic applicability of this new biotransformation. Studies in both directions are being carried out in our laboratory and will be published in due course.

\section{Notes and references}

$\uparrow$ Typical experimental procedure: In an Erlenmeyer under nitrogen atmosphere, containing the corresponding enzyme, a solution of internal standard (anisol) and acrylonitrile in toluene was incubated at $30{ }^{\circ} \mathrm{C}$ and 250 r.p.m. (orbitally shaken) for 5 minutes. Then, the secondary amine was added in order to initiate the reaction. The final concentrations of reactants were $0.05 \mathrm{M}$ amine and $0.1 \mathrm{M}$ acrylonitrile for reactions with amines $\mathbf{1}$ and $\mathbf{2}$, or $0.3 \mathrm{M}$ in both amine and nitrile for $\mathbf{3}$. Samples were withdrawn from the reaction and directly analysed by GC (100\% dimethyl polysiloxane capillary column, FID detection; oven temperature: from $60{ }^{\circ} \mathrm{C}$ to $160{ }^{\circ} \mathrm{C}$, rate of heating $\left.20{ }^{\circ} \mathrm{C} \mathrm{min} .{ }^{-1}\right)$. All the compounds were spectroscopically characterised $\left({ }^{1} \mathrm{H},{ }^{13} \mathrm{C}\right.$ NMR and MS) and analytically compared (GC) with true samples prepared by conventional methods. The reactions were run at least twice.

1 For some recent revisions, see: F. Secundo and G. Carrea, Chem. Eur. J., 2003, 9, 3194; N. M. Shaw, K. T. Robins and A. Kiener, Adv. Synth Catal., 2003, 345, 425; K. Drauz and H. Waldmann, Enzyme catalysis in organic synthesis: A comprehensive handbook, 2002, Wiley-VCH, Weinheim; M. Bertau, Curr. Org. Chem., 2002, 6, 987; M. T. Reetz, Curr Opin. Chem. Biol., 2000, 6, 145.

2 V. Gotor, Bioorg. Med. Chem., 1999, 7, 2189; F. van Rantwijk, M. A. P. J. Hacking and R. A. Sheldon, Monatsh. Chem., 2000, 131, 549; I. Alfonso and V. Gotor, Chem. Soc. Rev., 2004, 33, 201.

3 C. Branebby, P. Carlqvist, A. Magnusson, K. Hult, T. Brinck and P. Berglund, J. Am. Chem. Soc., 2003, 125, 874.

4 T. Kitazume, T. Ikeya and K. Murata, J. Chem. Soc., Chem. Commun., 1986,1331

5 V. Annamalai, E. F. DiMauro, P. J. Carroll and M. C. Kozlowski, J. Org Chem., 2003, 68, 1973.

6 M. Zahouily, Y. Abrouki, B. Bahlaouan, A. Rayadh and S. Sebti, Catal. Commun., 2003, 4, 521; D. Bhuniya, S. Mohan and S. Narayanan, Synthesis, 2003, 7, 1018 .

7 T. Ishida and S. Kato, J. Am. Chem. Soc., 2003, 125, 12035 and references cited therein. 